\title{
Not All Patients With Non-erosive Reflux Disease Share Psychological Distress as Main Mechanism of Disease
}

TO THE EDITOR: We read with interest the study by Nam et $\mathrm{al}^{1}{ }^{1}$ who evaluated the association between irritable bowel syndrome (IBS) and gastroesophageal reflux disease (GERD) and concluded that IBS is strongly linked to non-erosive reflux disease (NERD) and not with erosive esophagitis. The authors stated that the association between IBS and NERD is due to the fact that both disorders share psychological distress, such as somatization and anxiety.

However, we believe that it is deceiving to refer all patients with NERD to a unique pathogenetic mechanism represented by psychological distress. This population with typical reflux symptoms represents about $70 \%$ of GERD patients and it is simplistic to diagnose them exclusively on the basis of negative endoscopy, as Nam et al $^{1}$ have done. We have shown that NERD patients are an heterogeneous group from a pathophysiological point of view. ${ }^{2}$ The use of $\mathrm{pH}$-impedance testing allows us to identify 3 distinct subpopulations of $\mathrm{NERD}^{3-6}$ : the first with excess acid in esophagus, the second with normal acid, but an esophagus hypersensitive to acid or non-acid or both, the third without any kind of reflux underlying symptoms. This last subgroup is called functional heartburn $(\mathrm{FH})$ and must be excluded from the realm of GERD, as already acknowledged by the experts of Rome III criteria for esophageal functional disorders. We have also demonstrated that $\mathrm{FH}$ is significantly associated with dyspeptic symptoms pertaining to the postprandial distress syndrome, ${ }^{3}$ thus supporting also the fact that they are likely to be combined with IBS. $^{7}$ Therefore, the analysis of the Nam et al. did not take into any consideration the pathophysiological complexity of NERD and this reduces substantially the strength of their conclusions.

Moreover, Nam et al assessed also patients with atypical symptoms supposed to be due to reflux (hoarseness, chronic cough), but there was no mention of the methods they used in correlating them to reflux disease. It is well known that the rela- tionship of causality between reflux and extraesophageal symptoms is a controversial issue. ${ }^{8,9}$

Finally, Nam et $\mathrm{al}^{1}$ reported in their discussion that an increased body mass index may contribute to favor reflux and induce symptoms in NERD patients. Once again, it has been shown that this is only true for NERD patients with abnormal acid reflux and not for $\mathrm{FH} .{ }^{10}$

In conclusion, we believe that the results of the study by Nam et $\mathrm{al}^{1}$ should be interpreted with caution in relation to the above criticisms.

\footnotetext{
Edoardo Savarino, ${ }^{1}$ Patrizia Zentilin, ${ }^{2}$ Manuele Furnari, ${ }^{2}$ Giorgia Bodini, ${ }^{2}$ Elisa Marabotto ${ }^{2}$ and Vincenzo Savarino ${ }^{2}$

${ }^{1}$ Gastroenterology Unit, Department of Surgery, Oncology and Gastroenterology, University of Padua, Padua, Italy; and ${ }^{2}$ Gastroenterology Unit, Department of Internal Medicine, University of Genoa, Genoa, Italy
}

1. Nam SY, Ryu KH, Park BJ. Irritable bowel syndrome is associated with gastroesophageal reflux symptom but not erosive esophagitis. J Neurogastroenterol Motil 2013;19:521-531.

2. Savarino E, Zentilin P, Savarino V. NERD: an umbrella term including heterogeneous subpopulations. Nat Rev Gastroenterol Hepatol 2013;10:371-380.

3. Savarino E, Pohl D, Zentilin P, et al. Functional heartburn has more in common with functional dyspepsia than with non-erosive reflux disease. Gut 2009;58:1185-1191.

4. Savarino E, Marabotto E, Zentilin P, et al. The added value of impedance-pH monitoring to Rome III criteria in distinguishing functional heartburn from non-erosive reflux disease. Dig Liver Dis 2011;43:542-547.

5. Savarino E, Zentilin P, Tutuian R, et al. The role of nonacid reflux in NERD: lessons learned from impedance-pH monitoring in $150 \mathrm{pa}-$ tients off therapy. Am J Gastroenterol 2008;103:2685-2693.

6. Savarino E, Zentilin P, Tutuian R, et al. Impedance-pH reflux patterns can differentiate non-erosive reflux disease from functional heartburn patients. J Gastroenterol 2012;47:159-168.

7. de Bortoli N, Martinucci I, Bellini M, et al. Overlap of functional 
heartburn and gastroesophageal reflux disease with irritable bowel syndrome. World J Gastroenterol 2013;19:5787-5797.

8. de Bortoli N, Nacci A, Savarino E, et al. How many cases of laryngopharyngeal reflux suspected by laryngoscopy are gastroesophageal reflux disease-related? World J Gastroenterol 2012;18: 4363-4370.

9. Savarino E, Carbone R, Marabotto E, et al. Gastro-oesophageal reflux and gastric aspiration in idiopathic pulmonary fibrosis patients.
Eur Respir J 2013;42:1322-1331.

10. Savarino E, Zentilin P, Marabotto E, et al. Overweight is a risk factor for both erosive and non-erosive reflux disease. Dig Liver Dis 2011;43:940-945.

\section{Conflicts of interest: None.}

